4. Alexopoulos, C. \& Babitas, P. Age dependence of T lymphocytes (letter). Lancet 1976, i: 426.

5. De Paoli, P., Battistin, S. \& Santini, G.F. Age-related changes in human lymphocyte subsets: progressive reduction of the CD4 CD45R (suppressor inducer) population. Clin Immunol Immunopathol 1988, 48: 290-296.

6. Chandra, R.K. The relation between immunology, nutrition and disease in elderly people. Age Ageing 1990, 19: 25-31.

7. Caird, F.I., Andrews, G.R. \& Gallie, T.B. The leucocyte count in old age. Age Ageing 1972, 1: 239-244.

\section{Hyperplastic gingivitis: an oral manifestation of Wegener's granulomatosis}

Sir,

Apart from Fauci's' series in which $6 \%$ of his 85 patients with Wegener's granulomatosis had oral ulcers as one of the presenting signs and symptoms, the oral manifestations of this disease are rarely reported. ${ }^{2,3}$ I wish to report a patient with the limited form of Wegener's granulomatosis who presented with upper airway disease and hyperplastic gingivitis.

A 30 year old man presented with a one month history of frontal headache, epistaxis, left ear pain, deafness and blood-stained discharge and painful gum swelling associated with a weight loss of $4 \mathrm{~kg}$. He was afrebrile. The right nostril was obstructed by a fleshy growth which bled on contact. There was left ear otitis media and conduction deafness. Both the upper and lower gingivae were swollen and inflamed with petechial spots (Figure 1). Investigations included haemoglobin $14.0 \mathrm{~g} / \mathrm{dl}$, total white cell count $17.8 \times 10^{9} / 1$ without eosinophilia, erythrocyte sedimentation rate $120 \mathrm{~mm} /$ hour, serum creatinine $96 \mu \mathrm{mol} / 1$, normal urine microscopy, and normal chest X-ray. Computed tomography of the paranasal sinuses showed evidence of mucosal swelling of the maxillary and ethmoid sinuses bilaterally and a fluid level in the right maxillary sinus. Biopsy of the growth in right nasal cavity revealed histopathological changes consistent with a diagnosis of Wegener's granulomatosis.

He was started on prednisolone $60 \mathrm{mg}$ daily and cyclophosphamide $100 \mathrm{mg}$ daily. There was remarkable improvement in his constitutional symptoms. Three weeks later, the growth in his right nasal cavity and the painful gum swelling had completely regressed and his left ear had dried up.

In a review of 11 cases of Wegener's granulomatosis with oral manifestations reported in the dental and medical literature plus one case of their own, Handlers et $a l^{2}$ noted that hyperplastic gingiva is the most common oral lesion. The hyperplastic gingivitis starts in the interdental papilla areas and extends to the labial and buccal aspects. The gingiva is red to purple and has a granular appearance with many petechiae. Involvement of the whole gingiva and periodontium results in tooth mobility and loss of teeth.

Biopsy specimens of the gingiva frequently reveal pseudoepitheliomatous hyperplasia of the overlying epithelium, diffuse chronic histiocytic inflammation with

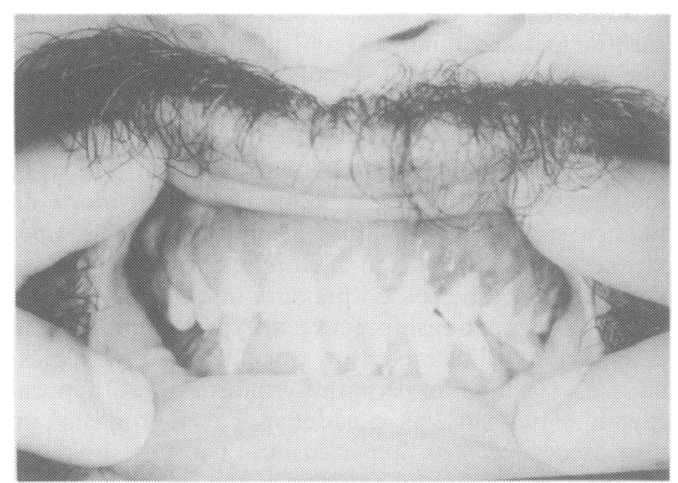

Figure 1 Swollen upper and lower gingivae with petechial spots.

occasional multinucleated giant cells and numerous eosinophils. ${ }^{2}$ Vasculitis and palisading granulomas, features found in classical lesions of Wegener's granulomatosis in the lungs and kidneys, however, are 을 rarely seen in the gingival tissue. Although a gingival biopsy was not performed for this patient, the regression $\mathcal{D}$ of the gum swelling and inflammation together with the $\frac{\mathbb{D}}{D}$ response to treatment of his other complaints show that the hyperplastic gingivitis is another manifestation of his disease.

In many of the cases in the review by Handlers $e t a f$ including three other recently reported cases in the dent literature, ${ }^{4,5}$ hyperplastic gingivitis is the initial manifes. tation of Wegener's granulomatosis. Therefore, hypert plastic gingivitis is a not uncommon presenting oral complaint in patients with Wegener's granulomatosis.

C.K. Liam Department of Medicine, University Hospital, $\overline{\mathrm{O}}$ Faculty of Medicine, University of Malaya, 59100 Kuala Lumpur, Malaysia.

\section{References}

1. Fauci, A.S., Haynes, B.F., Katz, P. \& Wolff, S.M. Wegener's granulomatosis: prospective clinical and therapeutic experience with 85 patients for 21 years. Ann Intern Med 1983, 98: 76-85.

2. Handlers, J.P., Waterman, J., Abrams, A.M. \& Melrose, R.J. Oral features of Wegener's granulomatosis. Arch Otolaryngol 1985, 111: $267-270$.

3. Cohen, P.S. \& Meltzer, J.A. Strawberry gums: a sign of Wegener's granulomatosis. JAMA 1981, 246: 2610-2611.

4. Cohen, R.E., Cardoza, T.T., Drinnan, A.J., Aguirre, A. \& N Neiders, M.E. Gingiva manifestations of Wegener's granulomatosis. J Periodontol 1990, 61: 705-709.

5. Glass, E.G., Lawton, L.R. \& Truelove, E.L. Oral presentation of Wegener's granulomatosis. J Am Dent Assoc 1990, 120: 523-525. 